\title{
Research on the Coordinated Development of Multiple Platforms of Ideological and Political Courses in the New Era
}

\author{
Junjun Song ${ }^{1}$, Jinfeng $\mathrm{Li}^{2}$ \\ ${ }^{1}$ School of Information Engineering, Sichuan Post and Telecommunication College, Chengdu, China \\ ${ }^{2}$ First Primary School in Tongchuan District, Dazhou, China \\ Email: Songjj999999@163.com
}

How to cite this paper: Song, J.J. and Li, J.F. (2022) Research on the Coordinated Development of Multiple Platforms of Ideological and Political Courses in the New Era. Open Access Library Journal, 9: e8488. https://doi.org/10.4236/oalib.1108488

Received: February 15, 2022

Accepted: March 6, 2022

Published: March 9, 2022

Copyright $\odot 2022$ by author(s) and Open Access Library Inc.

This work is licensed under the Creative Commons Attribution International License (CC BY 4.0).

http://creativecommons.org/licenses/by/4.0/ (c) (i) Open Access

\begin{abstract}
At present, with the deepening of the teaching reform of ideological and political theory courses, the proportion of ideological and political courses in the teaching reform of higher vocational colleges has increased significantly. The ideological and political construction of courses in higher vocational colleges is the requirement of the times to implement the fundamental task of establishing morality and cultivating people in higher vocational colleges, and it is the specific practice of ideological and political education in vocational colleges. Based on the basic concept of "co-construction, openness and sharing", an efficient, convenient and diversified communication platform is the guarantee for the collaborative education of ideological and political teachers, counselors, professional course teachers, and corporate mentors. How to strengthen the integration of teachers inside and outside the school and build a sharing platform relying on online and offline resources is a good reflection of the concept of higher vocational colleges coordinated promotion of curriculum ideological and political construction.
\end{abstract}

\section{Subject Areas \\ Politics, Education}

\section{Keywords}

Curriculum Ideology and Politics, Sharing Platform, Collaborative Education

\section{1. 多方协同推进课程思政建设研究现状}

\section{(一) 国内研究现状}


从国内的研究分析而言, 该主题研究包括, 第一, 专业课程的对接, 高 校思政课程与专业课程的融合来促进专业课教师落实课程思政。比如高国希 在《高校课程体系合力育人的理论逻辑》一文中坚持课程与育人相统一, 充 分发挥高校思想理论政治课与学科内容的育人标准统一, 更好地利用好课堂 这一主阵地、主渠道 [1]。这方面的研究对于现在专业教师对学生思政教育的 落实有一定的数据支撑, 并提出了自然科学和理工科课程与思政人文课程的 内在差异, 对于内在原因的分析较为充分。第二, 对于高校课程思政协同育 人机制的探索和路径思考方面。石丽艳在《关于构建高校课程思政协同育人 机制的思考》中提出课程思政的价值就在于要求每一个教师树立三全育人的 理念, 把每门专业课程和通识课程中的思政和德育元素充分发掘出来, 进而 发挥思想政治教育对大学生的价值引领[2]。第三, 关于课程思政教学育人过 程中, 课程思政和思政课程的关系分析, 姜冬乐与郭晓佳在《正确认识和把 握思政类课程与课程思政关系的研究》中指出两者在育人途径和目的上的一 致性决定了两者应当互助互利, 注重发挥课程思政和思政课程的协同效应 [3]。第四, 协同育人机制的构建能否打破思政课程、专业课程各自分隔现象 的研究。首先学者李仲涟提出的心理协同效应条件对后来学者研究协同理论 在教育领域方面的研究奠定了一定的基础[4]。其后, 不少学者在具体的课题 研究中强化协同育人的理念和方法, 使得协同育人的实施效果得到了发展和 正向验证。比如刘纯姣在《学校家庭协同教育构想》中提到将协同学的理论 应用于教育系统 [5]。史巍在《论以 “课程思政” 实现协同育人的关键点位及 有效落实》中提出高校思想政治教育是在长期探索中逐渐凸显重要性的, 课 程思政更是这项工作的重点。如何定位和协调好思政课程与专业课程的衔接, 教学内容和保障机制等方面的系统设计和构建是课程思政的重难点[6]。

(二) 国外研究现状

然而, 国外关于课程思政更多是对学生进行宗教教育、道德意识培养和 价值观引导、人格教育等方面展开研究。究其原因, 在于西方国家发展高等 教育由来已久, 他们在发展高等教育的过程中不断探索实践, 逐步形成了具 有自身国家特色和实际情况相契合的课程思政育人的有效方式和较为完善的 教学方式方法。比如, 美国明确设置了显性课程和隐形课程, 通过实质性的 思想政治教育和渗透式的教学方式要求教师适度结合教书育人, 重视学生学 习的主观能动性。此外, 德国专门设置相应的显性课程用于明确给学生进行 思想政治教育, 更多是通过专业学科的渗透和心理健康教育的重视来进行学 生相应的思政教育。一定程度上他们的思政教育实践和探索所形成的成果和 内在共识能在中国具体制度环境下有一定的适切性。

\section{2. 多方协同推进课程思政的组织协同：基于协同创新视角}

（一）协同创新理论基础

协同创新, 即由自我激励的人员所组成的网络小组形成集体愿景, 借助 网络交流思路、信息及工作状况, 合作实现共同的目标[7]。协同创新应包括 三大核心构成要素: 围绕组织结构、组织文化以及组织成员的构建, 为协同 创新发展提供组织支持; 建立协同创新机制, 进行自组织的更新, 让创新发 
展突破原有的局限, 调集多样化的资源进行应用, 在更广阔的范围内有效利 用和协调创新活动, 从而提升竞争优势; 在应用协同创新上, 着重于在创新 过程进行革新, 突破传统的边界, 开展跨机构的合作, 建立战略联盟体系, 并在新的合作联盟基础上, 确认机构之间的利益范围与责任边界, 设定风险 分担与利益分配机制从而提升创新的效能 [8]。企业最早开始采用协同创新的 模式, 推动企业竞争力的发展。面临着环境的日益变化以及创新速度的加快, 协同创新的理念从企业组织向其他部门扩散, 尤其在高等教育领域得到了有 效应用。高校将协同创新放大到宏观层面, 实行产学研用一体化。企业、大 学以及研究机构在这个过程中, 各自投入优势资源与能力, 在政府等其他机 构的支持之下，尤其是在资金与资源的支撑下，共同进行技术与知识的创新。 从美国斯坦福大学的 “BioX 项目”、硅谷产学研 “联合创新网络” 等的经验 表明, 协同创新需要具备四个基本保障条件: 基于不同领域的合作平台建构、 科学有效的组织结构设计、高效的运行机制与管理、充足的经费资源投入保 障[9]。简言之, 协同创新视一个从沟通 - 协调 - 合作 - 协同的过程。而教育 是由政府主导, 以学校为载体的公共事业, 但教育发展从来不仅仅是政府、 学校两个主体的事, 需要全社会共同参与。高职院校多方协同课程思政育人 正是通过发挥多元主体的智能, 开展实证和理论研究, 交流思想和信息, 对 大学生思政政治教育产生积极影响, 无论从主体构成还是成果导向上, 都应 体现出鲜明的协同创新特征。

高职院校课程思政协同育人机制的构建不仅仅是简单的将校内 “三师” (思政教师、辅导员、专业课教师)和企业导师进行整合, 更多的是以思政教 育全过程为导向, 依托、借助专业课程、通识教育课程进行思政实践活动。 在教学实践活动中充分发挥广大教师在课程教学中的育人责任, 挖掘出各种 课程的思政资源, 使其与思政课程的思政资源同向同行, 形成育人合力。因 为在实际学生教学和管理过程中, 不仅仅局限于专职辅导员、思政课老师、 专业课老师等育人主题的教学工作和活动, 学校从校级层面本身就应当构建 多学科、多维度、全方位、系统性参与的协作机制, 形成互相支撑、协同联 动的教学育人体系。总体而言, 高职院校 “课程思政建设” 作为一个整体, 它不仅仅局限于某一单独的研究领域, 应该是综合性的, 是协同育人机制。 因此高职院校课程思政育人具有多方协同的根本特征, 对于其路径的研究基 于协同创新理论[10]。

（二）协同推进课程思政建设的组织和机制协同

思政课程教师、专职辅导员和专业课程教师、企业导师的四位一体协同 育人机制, 有利于改变思想政治理论课、综合素养课程和专业课程之间的 “孤 立” 局面, 更好地提高高职院校课程思政育人成果的实效性。四方协同共同 构建一体化的协同平台, 构建符合高职院校课程思政育人的网络型组织结构 模式, 如图 1。

其中, 专职辅导员和思政课教师是大学生思想政治教育的主要力量, 思 政教师的课堂教学和课后实践活动以及辅导员在班团活动、第二课堂、创新 创业教育等日常工作中的方方面面都潜移默化地发挥教育大学生成长成才; 此外, 专业课教师和企业导师不仅仅对大学生的专业理论知识进行传授, 


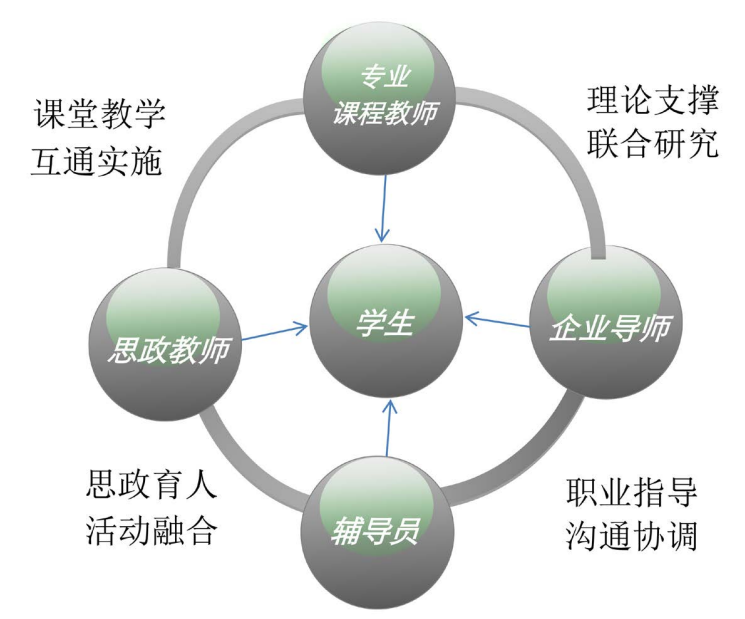

图 1. 高职院校课程思政育人的网络型组织结构模式图

培养学生的专业能力, 更要结合学生特点和专业发展将专业课程的思政育人 和教学进行深度融合。如图 1 所示的四方共同构建的协同平台, 在工作中能 重点围绕学生发展重点进行研究, 追踪研讨学生热点问题, 进行分析和教育 布局调整, 对学生思想动态和职业方面的价值观进行教育。可以图中的组织 机构中看到, 平台的搭建是紧紧围绕学生管理和教学开展的, 平台运行中实 际上还整合和多种类型的其他教学管理人员等主体, 不仅是图中的四方力量。 平台的最终目的是服务于大学生的思政教育, 促进大学生素质能力和价值观 的塑造, 这就需要加强思政课程教师、专职辅导员和专业课程教师、企业导 师质检真诚地沟通与理解, 搭建协同平台就是避免出现专业壁垒, 信息不对 称导致沟通不畅等情况, 提高平台协同育人工作效率。

高职院校的教育核心目的是育人, 育人工作中思政课程教师、专职辅导 员和专业课程教师、企业导师之间同步协调, 互相合作共同发挥力量, 推进 课程思政育人。搭建四方协同思政育人, 有利于减少沟通的障碍, 保证平台 的知识性、智慧性和实效性。

\section{3. 协同推进课程思政建设路径的保障机制}

\section{（一）管理机制}

目前, 在高职院校中思政课程教师、专职辅导员和专业课程教师、企业 导师在教学过程中的协同合作较少, 思政课老师和专业课教师重点强调知识 理论讲授、教学业务水平衡量和科研水平提升等方面; 专业辅导员工作更强 调对大学生思想和价值观的引领, 辅导员自身常规业务技能的培训和提升等 方面; 企业导师更侧重对大学生实践能力和对知识应用能力以及职业素养的 培养。高职院校在对这些师资队伍的协同育人工作的开展缺乏统一的管理机 制, 几方之间的教学活动更像各自为营, 较为缺乏协作的育人阵地。

针对高职院校学生特点, 首先高职院校从校级层面将课程思政的工作目 标纳入教学管理考核体系中, 将教学和学生工作进行共同目标的整合, 可以 建立课程思政师资管理队伍和相应的工作机制, 便于形成学术研究为需求的 团队, 比如大学生思政政治教育专题或者相关领域内的科学与实践研究。其 
次, 学校要建立合理的管理考核机制, 将教学和学生管理作为大学生思想教 育效果的教育责任主体, 充分调动思政课程教师、专职辅导员和专业课程教 师、企业导师的积极性和主动性, 完善几者之间的协同育人和研讨活动机制, 进一步保障他们对学生思政育人的合力。

\section{（二）经费保障机制}

高职院校在致力于打造协同推进课程思政育人工作平台时, 要充分考虑 到用经费和激励来保障多方协同育人工作的开展, 尤其是充足的经费保障是 推进高职院校课程思政育人工作的重点, 经费来源可以有校内以项目形势进 行投入; 也可是多方协同自身建设经费, 如专项课题、活动经费和专项培训 经费等。一是可以从学校层面设立专项经费, 用于推进协同课程思政育人工 作创新发展; 二是经费专项可以设置培训提升, 不同院系结合自身的专业特 点方面系统开展一系列专业课程和企业导师的思政理论提升培训, 通过较为 系统的常态化培训能从教师层面提升师资队伍的课程思政育人素养, 从而更 好提升协同育人工作的实效。

\section{（三）人员保障机制}

思政课程教师、专职辅导员和专业课程教师、企业导师这四类人员是推 进课程思政育人的主要成员。思政课老师主要通过课堂对学生进行思想政治 教育, 并辅以相应的思政活动; 专职辅导员则是通过学生的课堂和课后生活 中的思想政治指导; 专业课教师通过课堂进行专业技能的教学; 企业导师在 高职院校中尤其具有特色, 根据企业岗位生产实际的需求, 培养指导学生的 专业技术技能。只有这四个子系统的内在要素是为推进课程思政育人而努力, 发挥最大的协同合作力量, 才能使得整体效应最大化。课程思政育人教育需 要进一步增强教育活力。高职院校可以通过多方协同和体制机制创新, 通过 校企合作、产学研用等方式来形成教育研究和实践的整体协同效应。目前, 有的高职院校已经在协同育人方面进行了一定的尝试, 诸如专业课程教师担 任班主任, (有的学校称 “班导师” 制度)这种情况下, 学生的成长发展和职 业规划能够得到更加专业的指导; 辅导员担任生涯规划或市政理论课程教师, 基于辅导员对学生的了解较多, 在课堂教学中更能结合专业特色和学生特点 进行理论讲授和沟通; 兼职辅导员制度是指让教师担任班级辅导员, 通过让 授课教师从事辅导员的工作中, 让他们多多参与到日常生活中对学生的管理 和育人工作中去, 提升专业课教师、企业导师和思政老师对辅导员工作的了 解和认同, 便于更好进行一体化育人工作。教师队伍的双向奔赴和互通有无 才能更好促进协同推进课程思政育人的实现。

(四) 配套政策激励保障机制

高职院校协同推进课程思政建设主导机构是高职院校, 作用对象是学生。 因此在校内等方面给予了多方协同工作基本保障。同时根据高职院校本身职 业教学特点和合作的实践企业特点, 合作的企业也全力支持多方协同推进课 程思政育人工作的开展。比如高职院校具有高等教育和职业技能培养的双重 性质, 其教学目标就是培养具有高素质的技能人才。因此转变高职院校传统 的轻素养, 重技能的教学观念尤为重要, 加强对辅导员和思政教师的重视也 是首要问题。因此, 在抓好思政育人实效的同时要重视教师对成效的贡献程 
度, 按照实质性的贡献对平台的成员进行绩效评价, 评价采用定性和定量考 核相结合、年度考核与综合考核相结合的办法, 考核要求注重任务完成质量 和实际性贡献。而且在大数据时代, 通过相关技术支持企业尤其是校企合作 的企业签署相关联合教学的协议, 其中关于思政元素的挖掘和体现尤为重要, 系统总结出课程思政建设中的问题和经验, 共享研究成果和数据信息, 为参 与思政育人工作的各方力量提供数据支撑和基本信息的保障。

此外, 为了保障已经建立的多方协同机制持续高效运行, 形成协调统一 的内部管理体系, 规范和加强该机制的建立和运行管理, 需要在运行过程中 制定一系列制度和管理办法, 诸如多方协同推进课程思政育人平台的组建和 分工框架协议制度、科研组织和协同研究管理办法、评价和考核管理制度、 财务管理办法、成果奖励办法等等。

\section{4. 结语}

高职院校打造课程思政建设的多方协同平台不是单独建立行政管理机 构, 而是建立互相学习发展的共同体。打破思政教育壁垒, 推动学生管理和 专业教学之间在思政育人方面的融合发展, 在充分调动多方(思政教师、辅导 员和专业课程教师、企业导师)思政育人的积极主动性和创造性, 提高高职院 校整体思政育人实效的同时, 也切实推进了教师之间的互动和一体化发展。 在高职院校扩招的背景下, 无论是专业课程还是思政课程的实施对象范围都 有了一定的扩大, 而且在对课程思政具体实施方面更多是在探讨挖掘出专业 课程的思政元素, 呈现出散点式的研究特点, 并没有凸显如何加强思政教师、 辅导员和专业课程教师、企业导师之间的共同协作, 在多方协同育人的路径 方法上研究思路较少。笔者尝试从协同创新视角构建 “思政课程教师、专职 辅导员和专业课程教师、企业导师” 多方协同推进课程思政建设的模式, 来 促进课程思政建设的深入和落地。以协同育人理念为基础, 构成 “初步实践、 积极总结、进一步提升、反馈反思、研究深化、再次实践” 的螺旋上升式推 进过程的机制。才能发挥协同育人最大效应, 实现课程思政育人的目标, 更 好地提高高职院校课程思政育人成果的实效性。

本文以构建多元协同平台为研究主题, 首先是对相关研究文献和基础进 行研读分析, 通过对课程思政理论依据和实践特点, 尤其是高职院校企业导 师这一特色, 以协同创新视角对高校课程思政育人机制的构建提出了相应的 建议, 最终构建了符合高职院校课程思政育人的网络型组织结构模式并提出 了相应的保障机制。笔者在研究过程中缺乏较多的实证调研, 是只对个别高 职院校思政育人机制构建工作进行的调查, 对现实中课程思政建设存在的具 体问题缺乏深入的了解。笔者尝试性提出的相关问题和对策建议是通过对政 策文件的研读和理论演绎, 欠缺研究成果的普适性和可操作性。在未来, 该 课题的研究仍需要进一步扩大研究对象的范围, 并对文中提到的问题进行深 入剖析。

\section{基金项目}

四川邮电职业技术学院一般课题《高职院校多方协同推进课程思政育人 
的实践与探索》(YDXJKY202060)阶段性成果。

\section{Conflicts of Interest}

The authors declare no conflicts of interest.

\section{References}

[1] 高国希, 叶方兴. 高校课程体系合力育人的理论逻辑 [J]. 中国高等教育, 2017(23): 10-13.

[2] 石丽艳. 关于构建高校课程思政协同育人机制的思考 [J]. 学校党建与思想教育, 2018(10): 41-43.

[3] 姜冬乐, 郭晓佳. 正确认识和把握思政类课程与课程思政关系的研究 [J]. 工业和 信息化教育, 2021(3): 29-32.

[4] 李仲涟. 论心理的协同效应[J]. 湖南师范大学社会科学学报, 1987(5): 1-6.

[5] 刘纯姣. 学校家庭协同教育构想 [J]. 怀化师专学报, 1996(3): 328-330.

[6] 史巍. 论以“课程思政”实现协同育人的关键点位及有效落实 [J]. 学术论坛, 2018, 41(4): 168-173.

[7] Collaborative Innovation Network. https://en.wikipedia.org/wiki/Collaborative innovation network

[8] 熊励, 孙友霞, 蒋定福, 刘文. 协同创新研究综述-—基于实现途径视角 [J]. 科 技管理研究, 2011, 31(14): 15-18.

[9] 何郁冰. 产学研协同创新的理论模式[J]. 科学学研究, 2012, 30(2): 165-174.

[10] 苑大勇. 高等教育协同创新: 理论建构与演进 [J]. 高校教育管理, 2015，9(3): 16-21+29.

\section{Appendix (Abstract and Keywords in Chinese) 新时代课程思政多元平台协同发展研究}

摘要: 当前, 随着思想政治理论课教学改革的深入推进, 课程思政在高职院 校的教学改革中的比例显著提升。高职院校课程思政建设是落实高职院校立 德树人根本任务的时代要求, 是高职院校课程思政育人的具体实践。而基于 “协同共建、开放共享” 的基本理念, 高效便捷、多元化的沟通平台是思政 教师、辅导员、专业课教师、企业导师协同育人的保障。如何加强校内外师 资融合, 依托线上线下的资源建立共享平台, 正是高职院校协同推进课程思 政建设路径理念的较好体现。

关键词：课程思政，共享平台，协同育人 